\title{
BRAGANTIA
}

\section{Passado Recente, Presente e Próximos Passos}

$\mathrm{B}$ ragantia é o periódico científico editado pelo Instituto Agronômico (IAC), criado em 1941, com o intuito de publicar textos originais que contribuam para o desenvolvimento das Ciências Agrárias. Ao longo das quase sete décadas de existência, Bragantia tem se firmado como um dos mais tradicionais e respeitados periódicos brasileiros, sendo publicada de forma ininterrupta desde sua criação. Tal condição de destaque foi conquistada pelo brilhante papel desempenhado pelos seus editores científicos e funcionários, cuja atuação merece o respeito de todos e em especial do nosso querido IAC.

Em abril de 2009, assumi a delicada e desafiadora função de editor-chefe de Bragantia, da qual era editor associado na Área de Ciências Básicas. Delicada, por avaliar e tratar da divulgação dos dados obtidos em projetos de pesquisa por colegas com reconhecida competência e, ao mesmo tempo, desafiadora, pelo fato de manter a qualidade da publicação. Nesse quesito, cabe o agradecimento ao colega Dr. Oliveiro Guerreiro Filho, cujo trabalho abnegado elevou a importância de Bragantia no cenário nacional e internacional nessa última década.

Aumento expressivo no número de trabalhos publicados ocorreu a partir de 2004 (Figura 1), vindo a comprovar a demanda por parte de pesquisadores e profissionais atuantes na área de Ciências Agrárias. Na última década, houve aumento de três vezes na quantidade de textos publicados por Bragantia, sendo essa uma consequência da dedicação dos autores, dos revisores, do Comitê Editorial, do IAC e das agências de fomento (CNPq e Fapesp). Em 2009, os textos completos de Bragantia foram acessados mais de 350.000 vezes, com média superior a 950 acessos diários. Em relação ao fator de impacto, Bragantia tem apresentado contínuo aumento desse índice de desempenho, chegando a 0,308 (Figura 1), conforme dados da SciELO tendo como ano-base 2008.

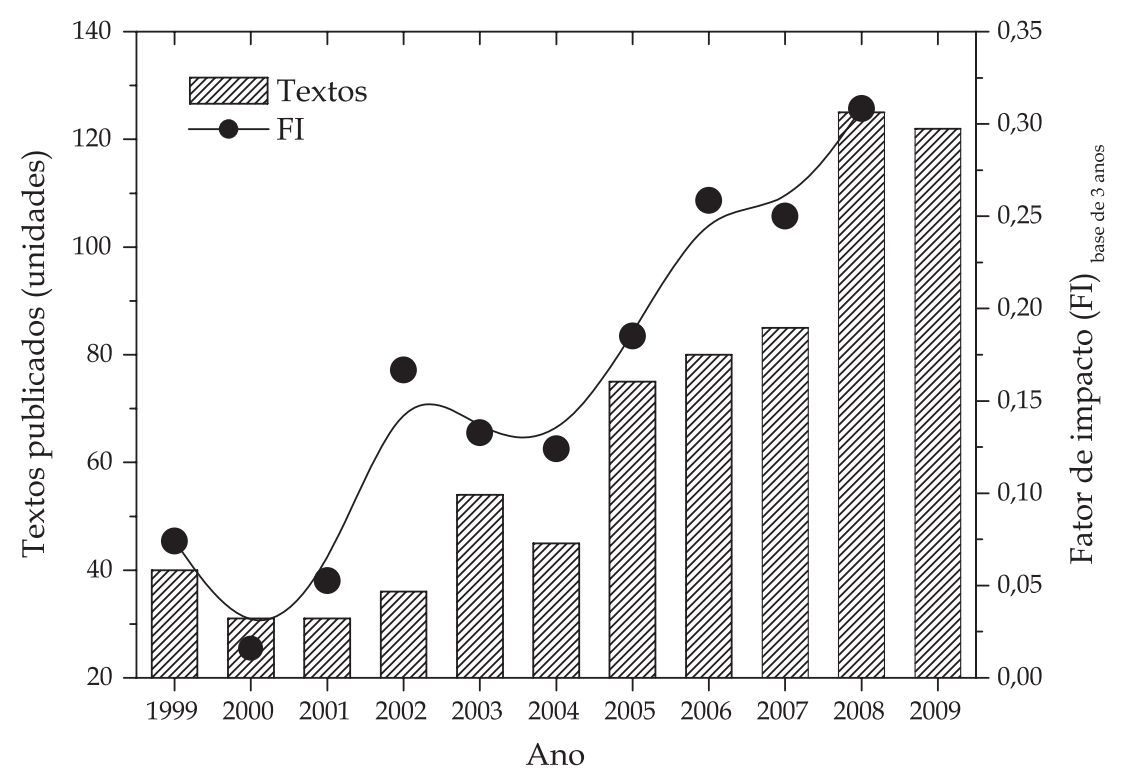

Figura 1. Variação temporal da quantidade de textos publicados em Bragantia entre 1999 e 2009 e do fator de impacto na base SciELO. 
O crescente interesse em Bragantia, como veículo de divulgação de pesquisa original, é também uma consequência da indexação em bases de dados nacionais e internacionais, como Abstracts on Tropical Agriculture, Bibliografia Brasileira de Agricultura, Bibliography of Agriculture (Agricola), Biological Abstracts (Biosis), CAB Abstracts, Herbage Abstracts, Plant Breeding Abstracts, Field Crops Abstracts, SciELO, Scopus e Redalyc. Na plataforma da SciELO, Bragantia está disponível há 12 anos e foi incluída no Programa TEAAL - Cornell University Rockefeller Foundation. Desde 2006, foi indexada pela International Society for Pest Information (ISPI) e convidada, em 2007, para indexação na coleção Redalyc (Red de Revistas Científicas de América Latina, El Caribe, España y Portugal).

No momento em que aceitei a função de editor-chefe, assumi um compromisso pessoal com algumas metas, sempre com o intuito de melhorar a qualidade e a divulgação de Bragantia. A implementação do sistema de gerenciamento eletrônico era uma meta na ocasião. De fato, o sistema eletrônico de submissão e gerenciamento de trabalhos funciona desde agosto de 2009, cujos frutos já são colhidos. Redução expressiva no tempo de avaliação dos trabalhos (inferior a seis meses) e dos custos editoriais são apenas alguns dos benefícios. Importante ressaltar o primordial papel da SciELO no suporte técnico ao sistema Submission (http:// submission.scielo.br). Outras metas são a renovação no quadro de editores associados e o aumento na divulgação nacional e internacional dos trabalhos publicados. Em breve, solicitaremos a indexação de Bragantia na base de dados ISI Web of Knowledge, a qual determinará maior inserção internacional do nosso periódico.

Finalmente, ratificamos nossos votos de sucesso e prosperidade para todos os colegas envolvidos com a divulgação científica, em especial aos autores, editores, revisores e funcionários de Bragantia.

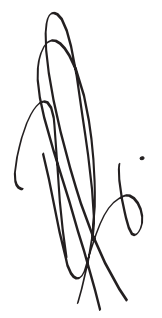

Rafael Vasconcelos Ribeiro

Editor chefe / Bragantia 